\title{
CLIMATIC ROLE OF SOUTHERN HEMISPHERE EXTRATROPICAL CYCLONES AND THEIR RELATIONSHIP WITH SEA ICE
}

\author{
by Ian Simmonds
}

(with one table and four text-figures)

\begin{abstract}
SIMMON\$S, I., 1996 (xi): Climatic role of Southern Hemisphere extratropical cyclones and their relationship with sea ice. In Banks, M.R. \& Brown, M.J. (Eds): CLIMATIC SUCCESSION AND GLACIAL HISTORY OF THE SOUTHERN HEMISPHERE OVER THE LAST FIVE MILLION YEARS. Pap. Proc. R. Soc. Tasm. 130(2): 95-100. https://doi.org/10.26749/rstpp.130.2.95 ISSN 0080-4703. School of Earth Sciences, University of Melbourne, Parkville, Victoria, Australia 3052.
\end{abstract}

\begin{abstract}
Transient atmospheric systems play a central role in determining the climate of the high southern latitudes. Accordingly, the variability of these features and the mechanisms which cause it are important considerations for the (palaeo)climatoløgist. One element which might have been expected to be intimately tied up with cyclonic activity is the extent of sea ice encircling the Antarctic continent.

We refer to studies which suggest relationships between sea ice and cyclones on synoptic time-scales, but in which these become very weak when interannual relationships are considered. We have analysed the reasons for this apparently contradictory behaviour. It is suggested that the intuitive appeal of an ice-cyclone connection has an implicit and characteristic time-scale (of a few hours or days) associated with it. However, the same reasening cannot be applied to longer periods, because of the nonlinearities in the links between the two factors. This, in particular, cautions against the use of simplistic arguments when trying to estimate the locations of storm tracks during epochs when seaice coverage was very different from that obtaining during the instrumental record.
\end{abstract}

Key Words: cyclones, variability, poleward transport, sea ice, accumulation, El Niño, Antarctica, baroclinicity, fluxes.

\section{INTRODUCTION}

One of the main "tasks" of the atmosphere (and to a lesser extent, the ocean) is to redress the latitudinal imbalance of the net radiation by transporting energy (in the form of latent, sensible and potential components) from the tropics to high latitudes. Virtually all of this transport in the middle and high latitudes is effected by large-scale wave activity. An important difference between the two hemispheres in the operation of this process is that in the north a significant proportion is accomplished by the "stationary" waves; in the Southern Hemisphere ( $\mathrm{SH}$ ), by contrast, virtually all of the poleward flux of energy results from the presence of "transient" disturbances (Peixoto \& Oort 1992). These can be thought of as the mobile highs, lows and frontal systems which are ubiquitous features of the southern extratropics.

Given this, it is clear that changes or variations in the characteristics (e.g. frequency, intensity) of SH extratropical cyclones may influence not only "weather" along the "storm tracks" but also climates, both to the north (say, the subtropics) and the south (Antarctica and its environs). For example, Connolley \& King (1993) showed that total column moisture over East Antarctica displays an interannual variation of about $10 \%$ of its mean value. As already indicated, this variability must be closely associated with the changes of eddy moisture transports in the high southern latitudes. Cullather et al. (1996) also found a strong interannual variability of the atmospheric moisture convergence over the continent, and Budd et al. (1995) recently emphasised the role of cyclonic systems in transporting moisture from the southern oceans to the Antarctic icecap. Variations in these aspects of climate have implications for the mass balance of the continent on long time-scales. One of the goals in the West Antarctic Ice Sheet Initiative Science Plan (Bindschadler 1995) is to establish the associations between sea ice and cyclone occurrence.

The atmosphere behaves, in many respects, as a turbulent fluid and exhibits variability (e.g. interannual variability or long-period oscillations), even in the absence of changes in the "boundary values". Hence, the numbers and tracks of lows can change from year to year (and from epoch to epoch), purely as a result of the chaotic nature of the system. The lows obviously also respond to changes in, for example, conditions at the surface. One important characteristic of the surface at high southern latitudes is the extensive coverage of sea ice. Therefore, it seems reasonable that variations in extratropical cyclone behaviour could influence the sea ice (through heat and moisture transport from the north and mechanical action on the pack). On the other hand, it could be thought that the condition of sea ice could influence cyclones and their developments, through modification of the surface fluxes of heat, moisture and momentum, and of the location of the baroclinic zone. Hence, there is the potential for sea ice to influence and be influenced by the transient systems in the $\mathrm{SH}$. It follows clearly that this has implications for climate on longer time-scales. Our purpose in this paper is to explore the relationship between Antarctic sea-ice conditions and characteristics of extratropical cyclones.

\section{SEA ICE AND CYCLONES}

The idea of sea ice condition influencing cyclone behaviour, through its modulating effect on latent and sensible heat fluxes and on the position and strength of the baroclinicity, 
has a strong intuitive appeal. Any of these factors has the potential to alter cyclone characteristics. However, it should be mentioned that the mechanisms by which this potential is realised have yet to be fully clarified. For example, a great deal of work has been undertaken in connection with the behaviour of "explosive cyclones" in the North Atlantic, and the effect of surface sensible and latent heat fluxes on these systems has been found to be quite variable. Reed \& Simmons (1991) and Kuo et al. (1991) suggested that the effect of the fluxes may depend on the stage of development and the degree of atmospheric preconditioning. Watkins \& Simmonds (1995) showed that five-day numerical forecasts in the Antarctic region are sensitive to the nature of the sea-ice specification (and hence fluxes), but they found that the overall change in mean sea-level pressure in their ensemble of cases achieved only a modest degree of statistical significance. This may be consistent with the findings referred to above, in that their arbitrarily chosen cases would have contained examples of developing, mature and decaying systems. There is no reason to expect that the arguments presented should not apply to cyclonic systems in the high southern latitudes. Hence, it is clear that, while anomalous surface fluxes have the potential to alter cyclone behaviour, this potential may not be realised in all cases. On the orher hand, Lee (1995) recently demonstrated the possibility of a zonally localised storm rrack in the absence of any kind of local instability.

Efforts directed at identifying links between $\mathrm{SH}$ extratropical cyclones and sea ice from the observational record have frequently been only regional in scale and have used only a limited amount of data. Given the large interannual variability of sea ice, some of the conclusions reached by early studies may be valid only for the period concerned and may not be of general applicability. Examples of this may include the apparent relationship of sea ice to cyclone density and cyclogenesis reported by Ackley \& Keliher (1976), Carleton (1981) and Howarth (1983). It is difficult to tell from these works whether the inferred sea ice/atmosphere associations were genuine or merely arose through a coincidence of anomalies in the data sets used. Only a few studies have utilised more than twenty years of southern sea-ice data (e.g. Budd 1975, Mayes 1985, Carleton 1988). Mayes explicitly noted how a longer term climatology can differ greatly from studies involving less than five years data. Some recent observational analysis of the sea icecirculation link has focussed on shorter time-scale scudies, in the order of days to several weeks. These have been successful in demonstrating the spontaneous effects of individual warm air incursions and storm activity on sea ice extent (e.g. Jacobs \& Comiso 1993, King 1994), and recent work has shown the influence of sea-ice conditions on short-range weather forecasts (Watkins \& Simmonds 1995, Nomura 1995). Indeed, one of the goals of the First Regional Observing Study of the Troposphere (Turner et al. 1996) was to use the three month-long Special Observing Periods to determine how much of the variability of high-laritude cyclone behaviour is associated with variations of Antarctic sea ice. However, these studies may tell little about the connections between the interannual (or longer) variability of cyclones (and possibly climate) and sea ice. It is now becoming well established that the nature of the relationship between climate parameters may change according to the time-scales considered.

The studies cited above have been useful but do not present a reliable and long-term quantification of the links berween cyclones and sea ice presented in the literature.
This has been primarily due to the shortness of the time periods used in the past and the large amount of effort required to generate long periods of statistics that describe extracropical cyclone behaviour. These problems have been addressed by Godfred-Spenning \& Simmonds (in press), using two long data sets covering the 18 -year period from September 1973 to August 1991. Their sea-ice extent data were taken from those presented in Simmonds \& Jacka (1995) and comprise monthly values of northernmost exten at every $10^{\circ}$ of longitude. The extratropical cyclone daca was originally drawn from daily $\mathrm{SH}$ surface pressure analyses prepared by the Australian Bureau of Meteorology, covering the time period outlined above. The meteorological analyses were used to compile seasonal cyclone statistics, using a vortex tracking program described in Murray \& Simmonds (1991). This program is entirely objective and requires no manual intervention during execution. The data summaries can be manipulated to produce statistics describing the geographical distribution of many properties of cyclones, including spatial density, relative central pressure, eastward and northward velocity, and discribution of cyclogenesis and cyclolysis. An analysis of a 15-year version of this cyclone data set has been presented by Jones \& Simmonds (1993).

\section{TEST OF A CONCEPTUAL MODEL}

Godfred-Spenning \& Simmonds (in press) examined the statistical relationship between the interannual variation of winter (June-July-August) cyclone density in a given longitudinal sector and sea ice in the same region. $\left(30^{\circ}\right.$ longicudewide sectors of ice were compared to $25^{\circ}$ areas of cyclone density, the centres of these sectors being co-located.) Due to the asymmetry of Antarctic sea ice around the continent, it was found more informative to correlate sea ice with cyclones in latitudinal bands relative to the mean ice edge in the sector being considered. Accordingly, mean seasonal ice excent was taken at every $10^{\circ}$ longitude and was correlated with cyclone density in eight different $5^{\circ}$ laticude wide "strips". If one hypothesised that the regions of high cyclone density (or genesis) moved in sympathy with the location of the ice edge, one would expect, in the vicinity of the mean ice edge, negative correlations between cyclone numbers and ice extent and, to the north and south of this vicinity, positive but weaker correlations.

An efficient way of presenting the resulting large number of correlations is in the form of a contour plor, as shown in figure 1 . There are only a few regions which achieve significance at the $90 \%$ statistical confidence level (Simmonds \& Jacka 1995). The sense of the correlations of these regions indicates that more extensive winter sea ice in the eastern Weddell Sea and to the east of the Ross Sea is associated with more cyclones to the north of the climatological ice edge and less to the south. There appears to be an overall increase in cyclone numbers in the Ross Sea sector in heavyice winters.

Even though few of the correlations displayed are significant, it is possible that a subtle, yet observable signal may be extracted. The "zonal" averages of the correlacion coefficients plots were calculated and are displayed in figure 2 (for the four seasons). The mean values shown are quite small bur are usually positive (i.e. greater sea-ice extent is linked wirh more cyclones), reaching a weak maximum around $5^{\circ}$ south of the ice edge for all seasons. There is 


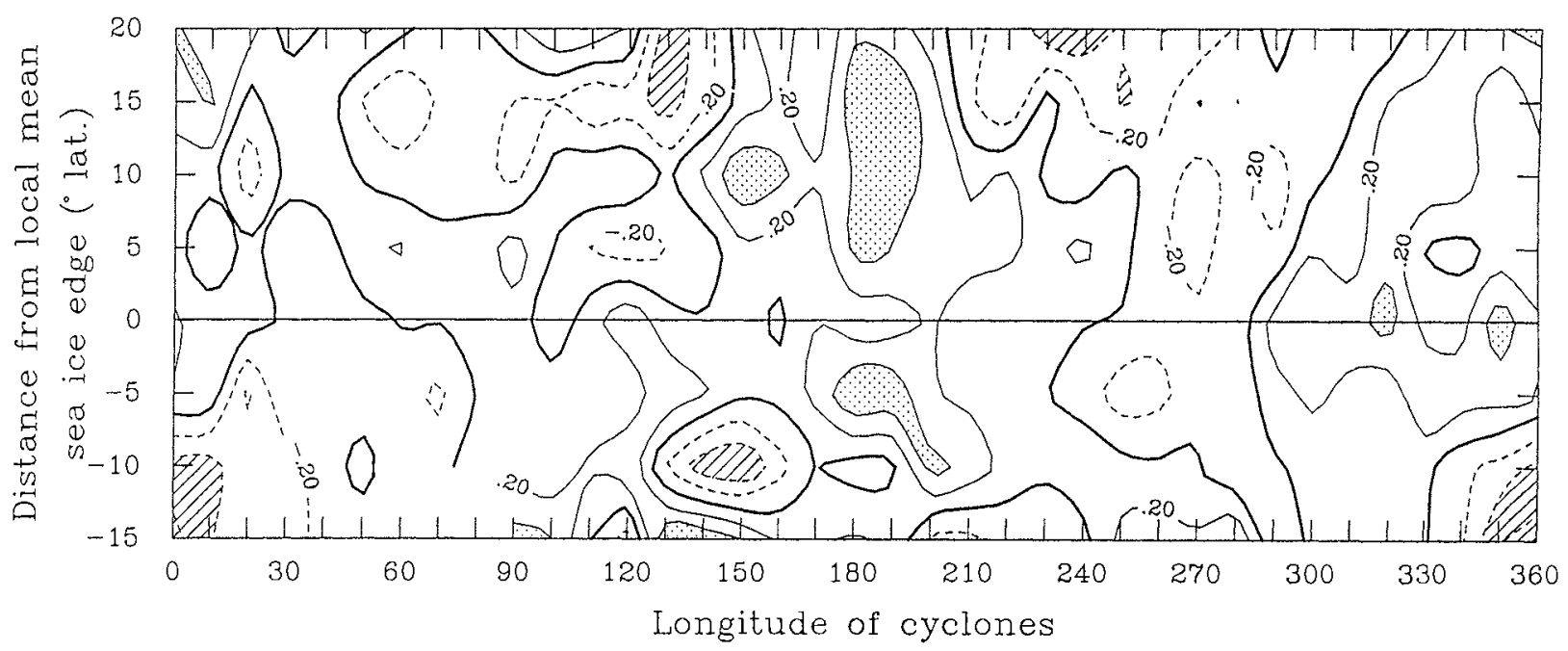

FIG. 1 - Correlation between the interannual variations of winter cyclone density (as a function of longitude and latitudinal distance from the mean ice edge) and co-located winter sea-ice extent. The horizontal axis indicates the central position of the sector of cyclones that are compared to sea-ice extent, while the vertical axis corresponds to the position of the latitudinal strip in relation to the mean winter sea-ice edge. The "zero latitude" ribbon occupies the same $5^{\circ}$ latitudinal zone as the mean sea-ice edge, and adjacent strips extend $15^{\circ}$ to the south and $20^{\circ}$ to the north. The contour interval is 0.2 ; negative contours are dashed. Coefficients $>0.4$ stippled; < -0.4 hatched; these can be deemed significantly different from 0 at the $90 \%$ statistical confidence level (Simmonds of Jacka 1995).

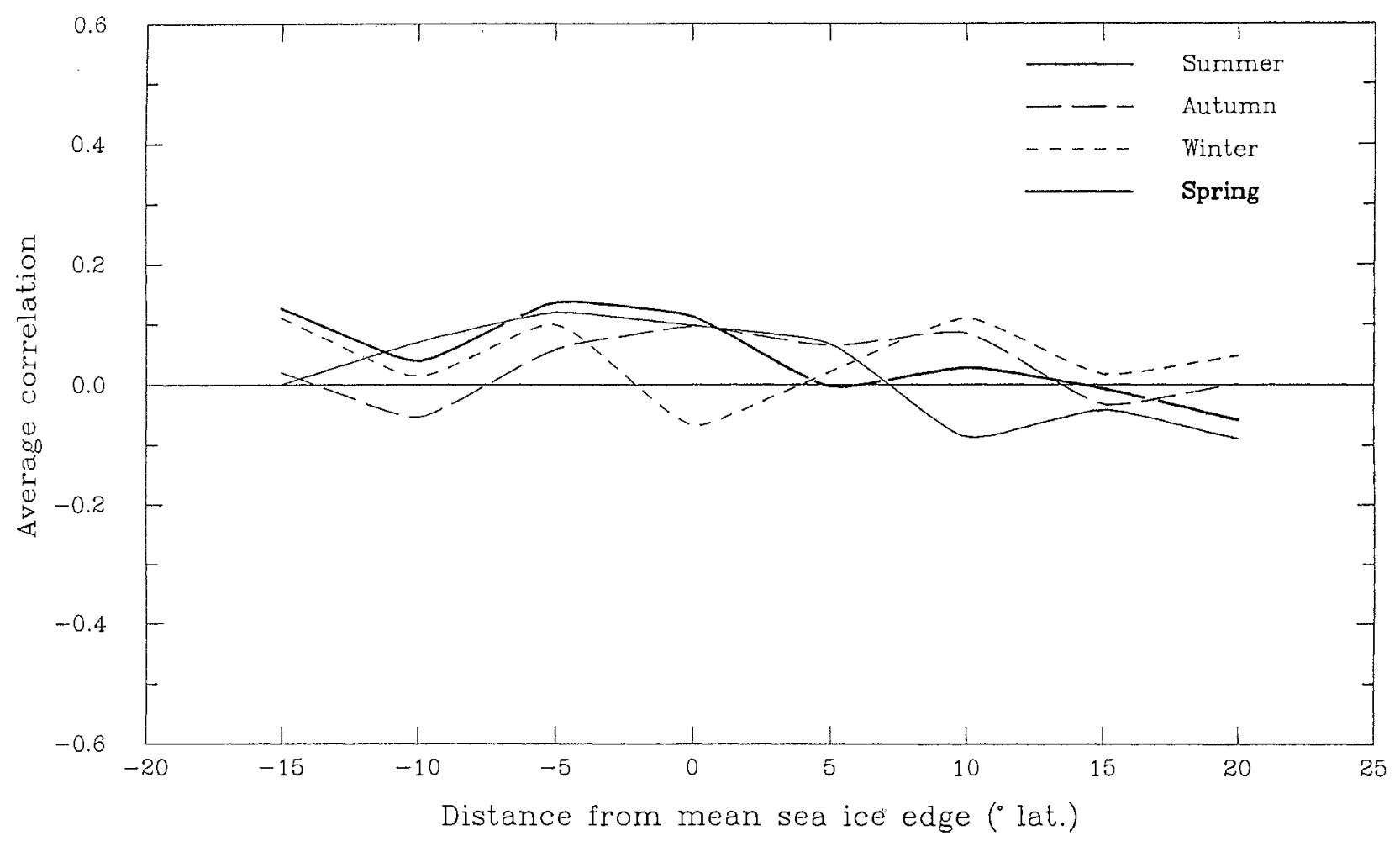

FIG. 2 - Longitudinal averages of the cyclone density-ice edge correlation plots for the four seasons. (The "Winter" case is the longitudinal averages of fig. 1.) The horizontal axis indicates the position of the latitudinal "strip" relative to the mean seasonal ice edge.

certainly no suggestion of overwhelmingly negative correlations in the vicinity of the ice edge.

It is possible that sea ice may have stronger associations with local cyclogenesis than with cyclone density. To explore this, the type of correlation analysis reported above was repeated for the rate of winter cyclogenesis, and the results were presented in a similar format. These show a patchy distribution of significant links (fig. 3), as for cyclone density; the typical magnitudes of the correlations are similar and there appears to be little relationship in winter between this cyclone statistic and sea ice. The strongest, albeit weak correlations indicate that more extensive sea ice is associated with greater cyclogenesis in the vicinity of the mean winter ice edge off Oates Land, in the vicinity of Prydz Bay and to 
the west of the Antarctic Peninsula. The "zonal" average of the correlations, similarly, exhibits very modest values (fig. 4); these values are predominantly positive and appear to assume their maximum in the vicinity of the ice edge.

These results are for "synchronous" (meaning here "same season") associations between ice and cyclones. However, given the inertias of the various parts of the climate system (and in particular the ocean) it is quite likely that the full effect of anomalous conditions may not be felt immediately. This certainly is true for the links between sea ice and the Southern Oscillation (Simmonds \& Jacka 1995). GodfredSpenning \& Simmonds (in press) have approached this by producing correlation contour plots (of the form shown in figs 1,3) for all seasons, with anomalies of sea ice both leading and lagging (by one season) and synchronous with cyclone density and cyclogenesis. For each plot, they determined the number of statistically significant (at the $90 \%$ confidence level) links found and expressed it as a percentage of the total number of points (i.e. 2880 [ $=8$ latitude belts $\times 360$ longitude sectors]). These values are shown in table 1. In general, the proportions do not differ greatly from the $10 \%$ one would expect to arise purely through chance, and these figures reinforce the impression of very weak associations

Notwithstanding this, it is interesting to note that, for the most part, by comparison correlations with sea ice lagging the cyclone statistics yield a greater percentage of significance than either the synchronous case, or with sea ice leading the cyclone-related data by one season. For all seasons and for both density and cyclogenesis, more than $10 \%$ of points were significantly correlated, reaching $15.4 \%$ for winter cyclogenesis.

\section{TEMPORAL DEPENDENCE OF RELATIONSHIPS}

Despite the apparent appeal of expecting a link between characteristics of SH cyclones and the extent of the sea ice edge, we have found, at best, only a very weak relationship on an interannual time-scale. This result is somewhat unexpected, and part of the reason for it may be that any associations may be restricted to given time-scales, or that the nature of the apparent relationship shows a dependence on the averaging

TABLE 1

Percentage of points on the "correlation plots" which achieved statistical significance*

Parameter Winter Spring Summer Autumn

Cyclones lag sea ice by one season

\begin{tabular}{|c|c|c|c|c|}
\hline Cyclone density & 8.4 & 10.1 & 13.5 & 8.0 \\
\hline Cyclogenesis & 9.3 & 9.4 & 10.1 & 8.4 \\
\hline \multicolumn{5}{|c|}{ Cyclones synchronous with sea ice } \\
\hline Cyclone density & 11.9 & 7.6 & 11.1 & 9.8 \\
\hline Cyclogenesis & 11.8 & 12.8 & 8.6 & 13.1 \\
\hline \multicolumn{5}{|c|}{ Cyclones lead sea ice by one season } \\
\hline Cyclone density & 12.5 & 13.9 & 10.4 & 12.2 \\
\hline Cyclogenesis & 15.4 & 14.0 & 12.3 & 11.2 \\
\hline
\end{tabular}

* At rhe $90 \%$ confidence level; sea-ice extent is correlated (leading, lagging, and synchronous) with the cyclone statistics for the season indicared. period considered. A factor often overlooked when the association of various climatic parameters is being examined is the dependence on the time-scale over which the various parameters are considered. The physics of the system may show how various meteorological elements are related to each other. In this relationship, there may be an implied time (and space) scale and, no matter how universally applicable they may appear, these relationships may not be appropriate to time-average data. To clarify these thoughts, suppose four climate variables are related through the simple equation

$$
A=B C D
$$

In our discussion above, we have made mention of the role that the flux of heat (and moisture) across the airsurface boundary plays in the generation and maintenance of extratropical cyclones. For illustrative purposes, we can approximate the full mathematical expression of this flux (Simmonds \& Budd 1990) in the form of the above equation, where $A$ is the heat flux, $B$ the temperature difference between the surface and the atmosphere, $C$ the wind speed, and $D$ the fraction of open water in the ice pack. In writing this relationship there is an implied time-scale of the order of, perhaps, hours. If we wish to know how the time average values of these four variables are related, we must apply a time-averaging operator to the above equation. When this is done, one obtains

$$
\bar{A}=\overline{B C D}+\overline{B C^{\prime} D}+\overline{C B^{\prime} D^{\prime}}+\overline{D B^{\prime} C^{\prime}}+\overline{B^{\prime} C^{\prime} D^{\prime}}
$$

where the primes denote instantaneous deviations from the long-term average (indicated by the overbar). This equation shows that the mean of $A$ is not given by the product of the means of $B, C$, and $D$ (which is the representation of the physics on the short time-scale), but that covariance terms enter the relationship. In many systems, these "noise" terms can be neglected, but this is not true around the periphery of Antarctica, where the covariances, such as that between temperature difference and wind speed, are known to assume significant proportions (e.g. Simmonds \& Dix 1989).

From this it can be seen that, while physical reasoning may suggest a specific relationship between surface fluxes (and, hence, cyclone characteristics) and ice conditions, such a relationship may not be valid when one is considering the connections between the averages of the quantities (e.g. the interannual variation of the seasonal averages). Even though not explicitly addressed here, this highlights the dangers of presenting simplistic arguments, suggesting changes in storm tracks during palaeo periods with very different ice conditions from today (e.g. in the Last Glacial Maximum). To a great extent, the location of the circumpolar trough (which has intimate connections with the density of cyclones) is dictated by the rotation rate of the Earth, and the characteristics of the surface appear to play a secondary role. For example, Simmonds \&. Wu (1993) found little sensitivity to its location, even when they removed all of the winter sea ice in a numerical model experiment.

\section{MODULATION BY THE EL NIÑO- SOUTHERN OSCILLATION}

It has become clear in recent years that the effects of the El Niño-Southern Oscillation phenomenon are not restricted to the tropics but that there are subtle but significant signals associated with it in the high southern latitudes. It is important to bear in mind that, whatever relationships there are between 


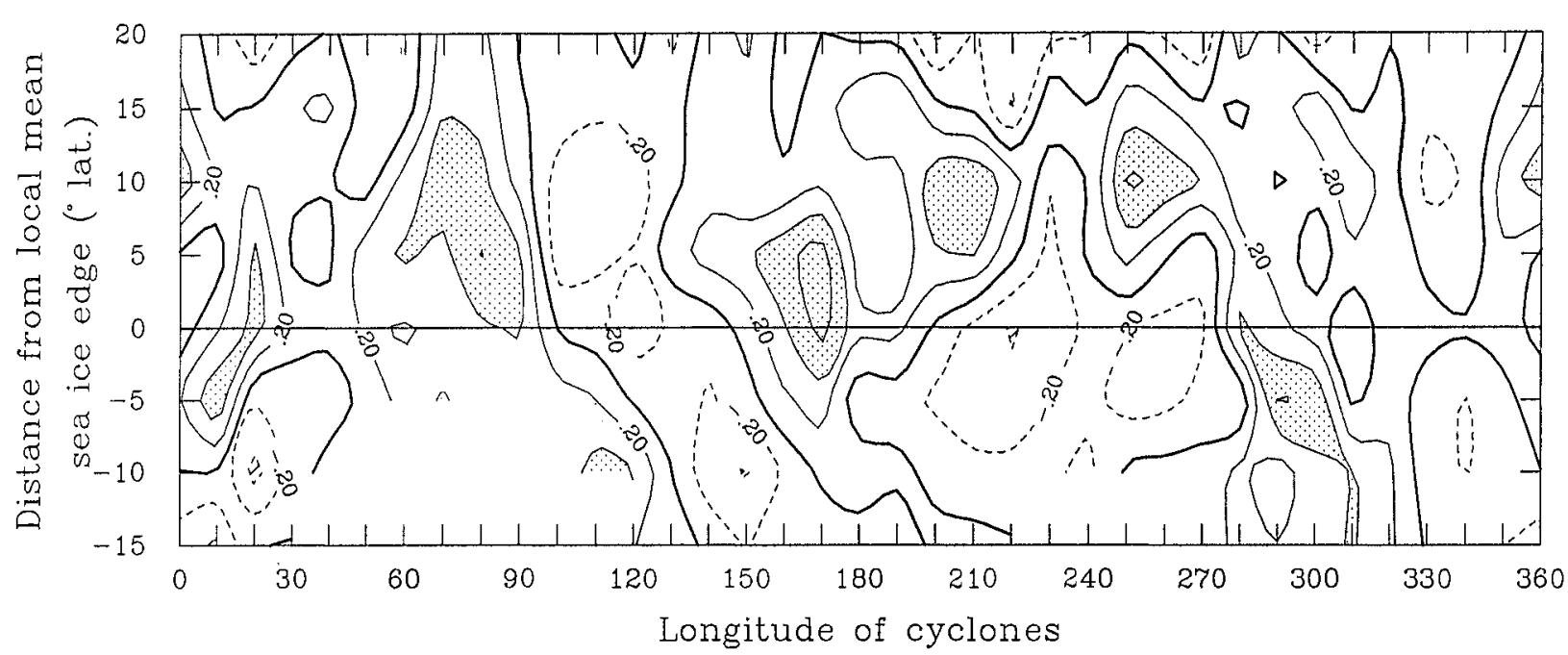

FIG. 3 - Correlation between the interannual variations of winter cyclogenesis density (as a function of longitude and latitudinal distance from the mean ice edge) and co-located winter sea-ice extent. The contour interval is $0.2 ;$ negative contours are dashed. Coefficients $>0.4$ are stippled; $<-0.4$ are hatched; these can be deemed significantly different from 0 at the $90 \%$ confidence level.

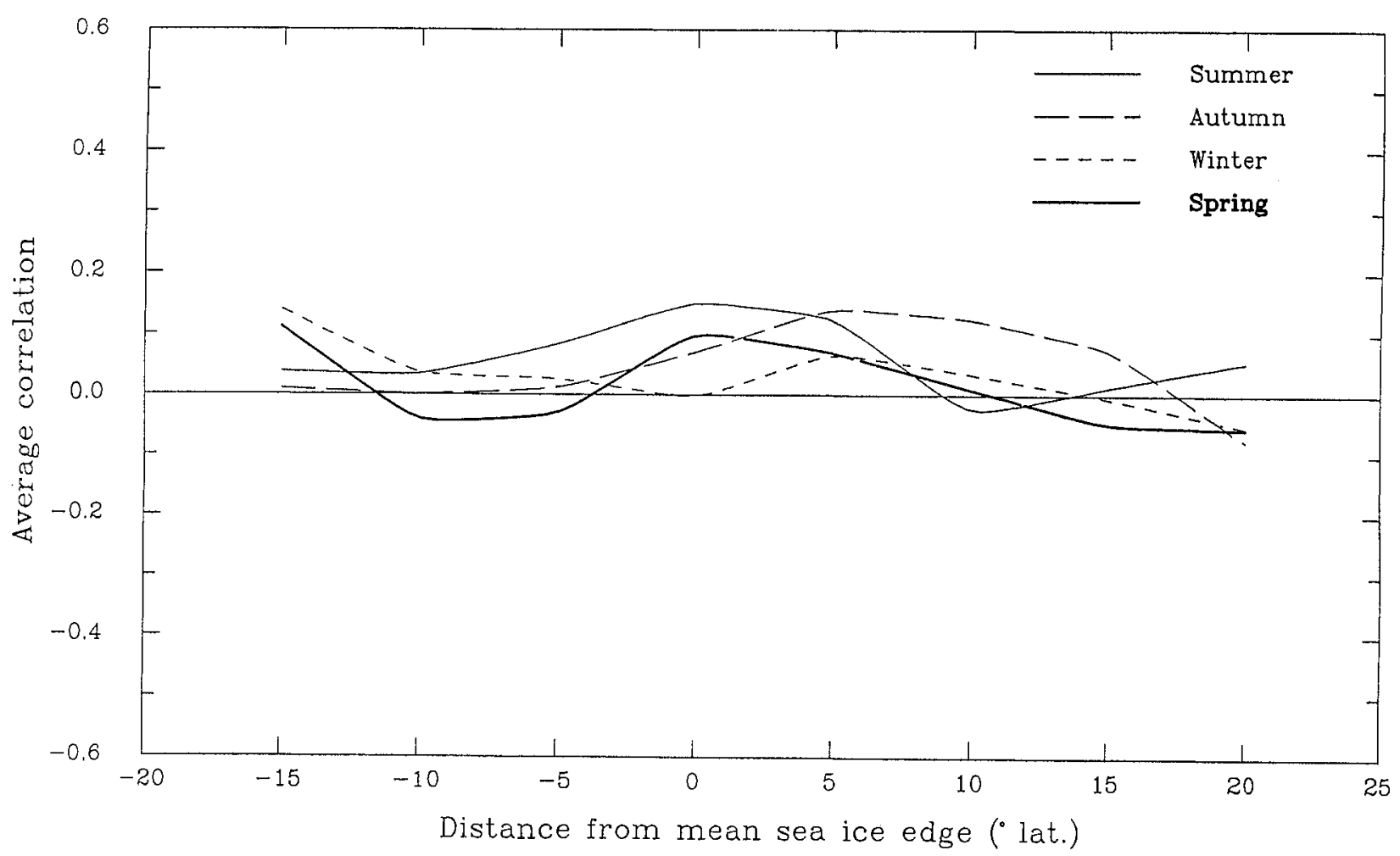

FIG. 4 - Longitudinal averages of the cyclogenesis density-ice edge correlation plots for the four seasons. (The "Winter" case is the longitudinal averages of fig. 3.)

seasonal cyclone behaviour and ice-edge deviations, these are almost certainly influenced by the long-period vacillations of the Southern Oscillation. For example, the work of Simmonds \& Jacka (1995) and Gloersen (1995) indicated that variations in sea ice extent are associated with El Niño-Southern Oscillation events. Other aspects of high southern latitude climate, such as temperature and pressure, also appear to be involved (Smith \& Stearns 1993). These associations and their stability are obviously complex. For example, the recent study of Cullather et al. (1996) showed there was a strong correlation between the Southern Oscillation Index and the moisture flux across a sector of the West Antarctica coast in the period up to 1990 , but a dramatic change in the relationship after that time.

\section{CONCLUDING REMARKS}

We have emphasised that the relationship between extratropical cyclone characteristics and sea ice extent is very complex, even when one restricts oneself to synoptic timescales. A number of studies have addressed the extent to 
which extratropical cyclone behaviour and sea ice distribution influence each other. Despite the attractiveness of arguments for direct relationships between these parameters on short time-scales, which may hold only for some synoptic systems, there appear to be, at best, only subtle connections on the interannual time-scales. (This result is consistent with the finding (e.g. Simmonds \& Dix 1986) that there appears to be little connection between the interannual variations in the strength of the circumpolar trough and the extent of winter sea ice.) There is a suggestion of a stronger relationship (in an averaged sense) when cyclonic conditions lead ice edge by one season, but this barely achicves statistical significance.

We have stressed that relationships between meteorological variables usually have an implicit time-scale associated with them. We have seen that these relationships may not apply to the time means (whether the mean is taken over seasons, decades, or palaeo epochs) of the features under consideration. The apparent contradiction becween the results mentioned above may be explained in terms of these arguments.

In discussing the nature of any links between sea ice and cyclones, we have restricted consideration of the former to changes in sea-ice extent. It is conceivable that, on seasonal and longer time-scales, cyclonic structure may be connected much more strongly with variations in sea-ice concentration. Simmonds \& Wu (1993) conducted numerical model experiments which suggest that this may be so. Unfortunately, while at present the scientific community has access to over 20 years of comprehensive and reliable data on the Antarctic sea-ice edge, equivalent satellite data on the distribution of ice concentration have only been available for a considerably shorter period.

\section{ACKNOWLEDGEMENT}

Part of this research was conducted with funds provided by the Antarctic Science Advisory Committee. This funding is gratefully acknowledged.

\section{REFERENCES}

ACKley, S.F. \& Keliher, T.E., 1976: Antarctic sea ice dynamics and its possible climatic effects. AIDJEX Bull. 33: 5376.

BindsCHADler, R.A. (Ed.), 1995: West Antarctic Ice Sheet Initiative: Science and Implementation Plan. National Science Foundation, Office of Polar Programs: 75 pp.

BuDD, W.F., 1975: Antarctic sea-ice variations from satellite sensing in relation to climate. J. Glaciol. 15: 417-427.

Budd, W.F., Reid, P.A. \& MinTY, L.J., 1995: Antarctic moisture flux and net accumulation from global atmospheric analyses. Ann. Glaciol. 21: 149-156.

CARleton, A.M., 1981: Ice-ocean-atmosphere interactions at high southern latitudes in winter from satellite observations. Aust. Meteorol. Mag. 29: 183-195.

Carleton, A.M., 1988: Sea ice-atmosphere signal of the Southern Oscillation in the Weddell Sea, Antarctica. J. Clim. 1: 379-388.

Connolley, W.M. \& King, J.C., 1993: Diagnostic studies of atmospheric water vapour transport to Antarctica, using radiosondes. Quart. J. R. Meteorol. Soc. 119: 325-342.

Cullather, R.I., Bromwich, D.H. \& Van Woert, M.L., 1996: Interannual variations in Antarctic precipitation related to El Niño-Southern Oscillation. J. Geophys. Res. 101: $19,109-19,118$

Glozrsen, P., 1995: Modulation of hemispheric sea-ice cover by ENSO events. Nature 373: 503-506.
Godrred-Spenning, C.R. \& Simmonds, I., in press: An analysis of Antarctic sea ice and extratropical cyclone associations. Int. J. Climatol. 16.

HOWARTH, D.A., 1983: An analysis of the variability of cyclones around Antarctica and their relationship to sea-ice extent. Ann. Assoc. Am. Geogr. 73: 519-537.

JACOBS, S.S. \& Comiso, J.C., 1993: A recent sea-ice retreat west of the Antarctic Peninsula. Geophys. Res. Lett. 20: 1171 1174 .

Jones, D.A. \& Simmonds, I., 1993: A climatology of Southern Hemisphere extratropical cyclones. Clim. Dyn. 9: 131145

KING, J.C., 1994: Recent climatic variability in the vicinity of the Antarctic Peninsula. Int. J. Climatol. 14: 357-369.

Kuo, Y.-H., ReED, R.J. \& Low-NAM, S., 1991: Effects of surface energy fluxes during the early development and rapid intensification stages of seven explosive cyclones in the western Atlantic. Mon. Weather Rev. 119: 457-476.

LEE, S., 1995: Localized storm tracks in the absence of local instability. J. Atmos. Sci. 52: 977-988.

MAYES, P.R., 1985: Secular variations in cyclone frequencies near the Drake Passage, southwest Atlantic. J. Geophys. Res. 90: 5829-5839.

MurRay, R.J. \& Simmonds, I., 1991: A numerical scheme for tracking cyclone centres from digital data. Part I: Development and operation of the scheme. Aust. Meteorol. Mag. 39: 155-166.

Nomura, A., 1995: Global sea ice concentration data set for use with the ECMWF re-analysis system. Tech. Rep. 76. European Centre for Medium Range Weather Forecasts, Reading, England.

Peixoto, J.P. \& OORT, A.H., 1992: PHYSICS OF CLIMATE. American Institute of Physics: $520 \mathrm{pp}$.

ReED, R.J. \& Simmons, A.J., 1991: Numerical simulation of an explosively deepening cyclone over the North Atlantic that was unaffected by concurrent surface energy fluxes. Weather and Forecasting 6: 117-122.

Simmonds, I. \& BUDD, W.F., 1990: A simple parameterization of ice leads in a GCM and the sensitivity of climate to a change in Antarctic ice concentration. Ann. Glaciol. 14: $266-269$.

Simmonds, I. \& Dix, M., 1986: The circulation changes induced by the removal of Antarctic sea ice in a July general circulation model. PROCEEDINGS OF THE SECOND INTERNATIONAL CONFERENCE ON SOUTHERN HEMISPHERE METEOROLOGY. Wellington, NZ, December 1986. American Meteorol. Society: 107-110.

SimmondS, I. \& Dix, M., 1989: The use of mean atmospheric parameters in the calculation of modeled mean surface heat fluxes over the world's oceans. J. Phys. Oceanogr. 19: $205-215$.

Simmonds, I. \& JACKA, T. H., 1995: Relationships between the interannual variability of Antarctic sea ice and the Southern Oscillation. J. Clim. 8: 637-647.

Simmonds, I. \& WU, X., 1993: Cyclone behaviour response to changes in winter Southern Hemisphere sea-ice concentration. Q. J. R. Meteorol. Soc. 119: 1121-1148.

SmITH, S. R. \& SteARNS, C. R., 1993: Antarctic pressure and temperature anomalies surrounding the minimum in the Southern Oscillation Index. J. Geophys. Res. 98: 13,07113,083.

Turner, J., Bromwich, D., Colwell, S., Dixon, S., Gibson, T., Hart, T., Heinemann, G., Hutchinson, H., Jacka, K., Leonard, S., Lieder, M., Marsh, L., Pendlebury, S., Phillpot, H., Pook, M. \& Simmonds, I., 1996: The Antarctic First Regional Observing Study of the Troposphere (FROST) Project. Bull. Am. Meteorol. Soc. 76.

Watkins, A.B. \& Simmonds, I., 1995: Sensitivity of numerical prognoses to Antarctic sea ice distribution. J. Geophys. Res. 100: 22,681-22,696.

(accepted 14 February 1996) 